\title{
The Influence of Perceived Leader Humor on Subordinate's Voice Behavior: A Study under Chinese Background
}

\author{
Zhiteng Lin \\ Jinan University, Guangzhou, China \\ Email:1174930805@qq.com
}

Received 5 April 2016; accepted 24 April 2016; published 27 April 2016

Copyright (C) 2016 by author and Scientific Research Publishing Inc.

This work is licensed under the Creative Commons Attribution International License (CC BY).

http://creativecommons.org/licenses/by/4.0/

(c) (i) Open Access

\begin{abstract}
Organization Behavior has paid more and more attentions on the impact of leaders' humor on employees. The leaders' humor plays an important role in the fight against organization silence as an important means to ease the work pressure and adjust the organizational climate. This study has surveyed 502 Chinese employees to explore the impact of leader's affiliative humor and aggressive humor style on employee voice behavior. The study found that the leaders' affiliative humor can significantly promote employee voice behavior, and aggressive humor suppress. Future researchers should pay more attention on the role of organizational factors that influence the process.
\end{abstract}

\section{Keywords}

\section{Affiliative Humor, Aggressive Humor, Voice Behavior}

\section{Introduction}

In the modern time, working pressures have impelled a number of personal and organizational issues. On the one hand, it would cause physical and psychological problem which impacted on human being's health and produced insomnia, anxiety, depression and other physiological imbalances to employees [1]. On the other hand, greater pressure would lead to negative emotions which hindered organizational communication and produce lower performance and organization violation. It is bad for the development of the organization. Deshpande thought that organization humor had an important role in fighting against organization silence and regulating organizational climate [2].

As the core of relationships and resources in the team, leaders' humor behavior will make effects on subordinates and groups [3]. Especially in the context of Chinese culture, the relationship between leader and subordi- 
nate relationship was influence by the traditional cultural of liege. Therefore, to explore the impact of leaders' humor on employee behavior has a profound practical meaning in Chinese culture.

At the same time, humor has been recommended in the positive organization behaviors as an interesting communication behavior [4] [5]. However, all of the humor style are positive? Obviously not. Those aggressive humor, with a sarcastic humor will reduce the efficiency of the organization and bring out the internal organizational conflict and estrangement [6]. In all, it had a devastating effect on the organization and staff. However, the negative effects of humor have been little studied [7].

Therefore, in the context of Chinese culture, the study had explored the impact of leaders' humor on the behavior of subordinates is necessary.

\section{Hypotheses}

Humorous social theory shows that humor is an interpersonal way, it is an ideological game [8]. People interact in a joy means to make fun and laughter in the group. Affiliative humor can give the recipient a positive emotional experience to ease the interpersonal tensions and improve relationships [9].

According to Fredrickson's expand-construction theory, we know that positive emotions expand their individual attention, cognition, and scope of action, so that the individual will become more open and construct more durable individual resources. It can promote interpersonal links, build social resources, and bring more social support. Meanwhile, the emotional events theory also tells us that positive emotions which triggered by work promote employees positive attitude and behavior.

Therefore, the positive leaders' humor in the organization plays a role through that it produces laughter and positive emotions which could promote communication and interpersonal relationship [10]. When the subordinate perceive leaders' affiliative humor, it will be explained a proactive interpersonal signal by subordinate to create a good atmosphere of communication in the organization [11]. To further enhance the subordinates' willingness to communicate, it can improve subordinates job satisfaction and job performance [12], as well as, it can also reduce the negative emotions of employees and some disadvantage organization behaviors, suchas organizational cynicism and dysfunctional resistance [13] [14].

The voice behavior is a behavior that subordinates make some constructive suggestions for the sake of improving the status of work and optimization of the organization [15]. It is an active interpersonal behavior. The leaders' affiliative humor make for producing positive emotions of subordinates, increasing willingness to communicate with others, thus it will promote subordinates make more constructive suggestions to the organization and leaders [16]-[18]. In this study, we make the hypothesis 1:

Hypothesis 1: subordinates perceived the leaders' affiliative humor can enhance voice behavior of subordinates

Similarly, according to the expand-construction theory, negative emotions will narrow individual actions and resources lead that the individual make self-protection measures to protect against damage, or even to harm the organization benefits [11]. According emotional events theory, negative emotions triggered by work events will affect employee attitudes and behavior. Negative emotions such as fear and anxiety may lead to reduce self-esteem, trust and security. Finally, it restrain voice behavior occurred.

Thus, while scholars mainly focus on the positive effect of humor [7], but we also know that humor is a double-edged sword. Mocking and sarcastic humor will weaken the leader-subordinate relationship, reduce the efficiency of organization [6], and make estrangement in the organization.

In other words, malicious, inappropriate and sarcastic leaders' humor will make subordinates feel anger, shame, fear, anxiety, or other negative emotions. Finally, it will affect employees' behavior such as slack work, organization silence and leaving. In another word, leaders' aggressive humor will influence subordinates' trust, self-esteem, or other cognitive activity, resulting in a judgment-driving behavior [19]. In the end, it suppress the occurrence of voice behaviors. In this study, we make the hypothesis 2 :

Hypothesis 2: subordinates perceived the leaders' aggressive humor can suppress voice behavior of subordinates

\section{Method}

\subsection{Sample and Procedure}

We collected data from employees in work units in different organizations in the Dongguan, Guanzhou, Hang- 
zhou, China, in company including technology, government, and internet. Firstly, we asked employee finish the humor style questionnaire. For the sake of overcoming the homology error, after two weeks, we then asked them finished the voice behavior questionnaire. We received a total of 523 employee responses out of 550 surveys (response rate for employee surveys $=95.1 \%$ ), the valid surveys were 502 out of 523 surveys (valid rate for employee surveys $=96.0 \%$ ). The employee respondents were 283 male and 219 female. They averaged 36.3 years.

\subsection{Measures}

Humor style. We measured leaders’ affiliative humor and aggressive humor style with Matrin's (2003) 16-item humor style scale. A sample item is "my supervisor usually don't laugh or joke around much with other people." Responses for these items were made on a seven-point response scale where $1=$ totally disagree to $7=$ totally agree. The reliabilities for leaders' affiliative humor were 0.872 . The reliabilities for leaders' aggressive humor were 0.834 .

Voice behavior. We measured employee' voice behavior with Van Dyne and Lepine (1998) 6-item voice behavior scale. Responses for these items were made on a five-point response scale where 1 = totally disagree to 5 = totally agree. Items were prefaced by "This particular co-worker” and ended with (1) "develops and makes recommendations concerning issues that affect this work group"; (2) "speaks up and encourages others in this group to get involved in issues that affect the group"; (3) "communicates his/her opinions about work issues to others in this group even if his/her opinion is different and Others in the group disagree with him/her"; (4) "keeps well informed about issues where his/her opinion might be useful to this work group"; (5) "gets involved in issues that affect the quality of work life here in this group"; and (6) "speaks up in this group with ideas for new projects or changes in procedures.” The reliabilities for voice behavior were 0.862 .

\section{Results and Discussion}

\subsection{Results}

Firstly, we analyzed the correlation of leaders' affiliative humor and aggressive humor which subordinates perceived with subordinates' voice behaviors. The results showed that: subordinates perceived leaders' affiliative humor and voice behavior was a significant positive correlation $(r=0.808, \mathrm{p}<0.001)$ to verify the hypothesis 1 ; subordinates perceived leaders' aggressive humor and voice behavior was a significant negative correlation ( $\mathrm{r}=$ $-0.769, \mathrm{p}<0.001$ ) to verify the hypothesis 2 . Specific results are shown in Table 1.

Meanwhile, Controlling leaders’ age, gender, subordinates' age, gender, education level subordinates, work experience and other factors, we had used the regression analysis. We found that the leader's affiliative humor positively predicted employees' voice behavior $(\beta=0.579$, $\mathrm{p}<0.001)$. We also knew that leader's aggressive humor negatively predicted employees' voice behavior $(\beta=-0.586, \mathrm{p}<0.001)$. It verified our assumptions. As shown in Table 2.

\subsection{Discussion}

From the above analysis, we can know that leader' affiliative humor will promote voice behavior. When the subordinates perceived the leaders' humor as affiliative humor, he will generate more positive emotion to the leader. Then it will increase more trust and communication between each other that will lead to subordinates make more advices.

However, the leader' aggressive humor will suppress voice behavior. When the subordinates perceived the leaders' humor as aggressive humor, he will generate more negative emotion to the leader. Then it will broke trust between employees with supervisor resulting in weakening the willing to give advices.

Table1. The correlation between subordinate perceived leaders' humor style and voice behaviors.

\begin{tabular}{ccccc}
\hline Variable & M & SD & 1 & 2 \\
\hline 1. leader' affiliative humor & 4.81 & 0.74 & 1 & $-0.815^{* * *}$ \\
2. leader' aggressive humor & 4.03 & 0.68 & $0.808^{* * *}$ & $-0.769^{* * *}$ \\
3. voice behavior & 3.43 & 0.72 & 1 \\
\hline
\end{tabular}

${ }^{* * *}$ Correlation is significant at $\mathrm{p}<0.001$ level (2-tailed). 
Table 2. The regression analysis of subordinate perceived leaders' humor style and voice behaviors after control extra variable.

\begin{tabular}{ccccc}
\hline Step & & Model 1 & Model 2 & Model 3 \\
\hline \multirow{3}{*}{ Step1 } & Leader's age & 0.128 & 0.097 & 0.105 \\
& Leader's gender & $0.233^{* *}$ & 0.195 & $0.206^{* *}$ \\
& Employee's age & 0.124 & 0.086 & 0.113 \\
& Employee's gender & 0.073 & 0.055 & 0.047 \\
Employee's education & 0.015 & 0.008 & 0.010 \\
& Employee's work experience & 0.119 & 0.118 & 0.118 \\
& Leader's affiliative humor & & $0.579^{* * *}$ & $-0.586^{* * *}$ \\
& Leader' aggressive humor & & & 0.591 \\
\hline
\end{tabular}

${ }^{*} \mathrm{p}<0.05 ;{ }^{* *} \mathrm{p}<0.01 ;{ }^{* * *} \mathrm{p}<0.001$.

Therefore, Leaders should pay more attention on positive humor to enhance relationships in the organization management. It will increase subordinates psychological security, thereby promoting the subordinate's voice behavior in order to facilitate the development of the organization; meanwhile, according to the characteristics of subordinates, Leaders should consciously reduce the negative humorous expression, so as to avoid the opposite effect.

Future research could study the mediate and modulate variables in that how leaders' humor affect employees' voice behaviors. It also can expand the theoretical model to study that how the positive humor influence organization, as well as negative humor.

\section{References}

[1] Berset, M., Elfering, A., Lüthy, S. and Semmer, N.K. (2011) Work Stressors and Impaired Sleep: Rumination as a Mediator. Stress and Health, 27, 71-82. http://dx.doi.org/10.1002/smi.1337

[2] Deshpande, R.C. (2012) A Healthy Way to Handle Work Place Stress through Yoga, Meditation and Soothing Humor. International Journal of Environmental Sciences, 2, 2143-2154.

[3] Kim, J. (2013) Structural Equation Modeling for Humor, Job Satisfaction, Job Stress and Intention to Turnover. Journal of Korean Academy of Nursing Administration, 19, 265-272. http://dx.doi.org/10.11111/jkana.2013.19.2.265

[4] Lehmann Willenbrock, N. and Allen, J.A. (2014) How Fun Are Your Meetings? Investigating the Relationship between Humor Patterns in Team Interactions and Team Performance. Journal of Applied Psychology, 99, 1278-1287. http://dx.doi.org/10.1037/a0038083

[5] Mesmer Magnus, J., Glew, D.J. and Viswesvaran, C. (2012) A Meta-Analysis of Positive Humor in the Workplace. Journal of Managerial Psychology, 27, 155-190. http://dx.doi.org/10.1108/02683941211199554

[6] Kauffeld, S. and Lehmann Willenbrock, N. (2012) Meetings Matter Effects of Team Meetings on Team and Organizational Success. Small Group Research, 43, 130-158. http://dx.doi.org/10.1177/1046496411429599

[7] Wisse, B. and Rietzschel, E. (2014) Humor in Leader-Follower Relationships: Humor Styles, Similarity and Relationship Quality. Humor, 27, 249-269. http://dx.doi.org/10.1515/humor-2014-0017

[8] Martin, R.A., Lastuk, J.M., Jeffery, J., Vernon, P.A. and Veselka, L. (2012) Relationships between the Dark Triad and Humor Styles: A Replication and Extension. Personality and Individual Differences, 52, 178-182. http://dx.doi.org/10.1016/j.paid.2011.10.010

[9] Martin, R.A., Puhlik Doris, P., Larsen, G., Gray, J. and Weir, K. (2003) Individual Differences in Uses of Humor and Their Relation to Psychological Well-Being: Development of the Humor Styles Questionnaire. Journal of Research in Personality, 37, 48-75. http://dx.doi.org/10.1016/S0092-6566(02)00534-2

[10] Romero, E.J. and Arendt, L.A. (2011) Variable Effects of Humor Styles on Organizational Outcomes. Psychological reports, 108, 649-659. http://dx.doi.org/10.2466/07.17.20.21.PR0.108.2.649-659

[11] Glomb, T.M, Bhave, D.P., Miner, A.G. and Wall, M. (2011) Doing Good, Feeling Good: Examining the Role of Organizational Citizenship Behaviors in Changing Mood. Personnel Psychology, 64, 191-223. http://dx.doi.org/10.1111/j.1744-6570.2010.01206.x 
[12] Robert, C., Dunne, T.C. and Iun, J. (2015) The Impact of Leader Humor on Subordinate Job Satisfaction the Crucial role of Leader-Subordinate Relationship Quality. Group \& Organization Management, 1-32. http://dx.doi.org/10.1177/1059601115598719

[13] Gkorezis, P., Petridou, E. and Xanthiakos, P. (2014) Leader Positive Humor and Organizational Cynicism: LMX as a Mediator. Leadership \& Organization Development Journal, 35, 305-315. http://dx.doi.org/10.1108/LODJ-07-2012-0086

[14] Goswami, A., Nair, P.K. and Grossenbacher, M.A. (2015) Impact of Aggressive Humor on Dysfunctional Resistance. Personality and Individual Differences, 74, 265-269. http://dx.doi.org/10.1016/j.paid.2014.10.037

[15] Maynes, T.D. and Podsakoff, P.M. (2014) Speaking More Broadly: An Examination of the Nature, Antecedents, and Consequences of an Expanded Set of Employee Voice Behaviors. Journal of Applied Psychology, 99, 87-112. http://dx.doi.org/10.1037/a0034284

[16] Detert, J.R. and Burris, E.R. (2007) Leadership Behavior and Employee Voice: Is the Door Really Open? Academy of Management Journal, 50, 869-884. http://dx.doi.org/10.5465/AMJ.2007.26279183

[17] Detert, J.R. and Edmondson, A.C. (2011) Implicit Voice Theories: Taken-for-Granted Rules of Self-Censorship at Work. Academy of Management Journal, 54, 461-488. http://dx.doi.org/10.5465/AMJ.2011.61967925

[18] Detert, J.R. and Trevino, L.K. (2010) Speaking up to Higher Ups: How Supervisors and Skip-Level Leaders Influence Employee Voice. Organization Science, 21, 249-270. http://dx.doi.org/10.1287/orsc.1080.0405

[19] Pundt, A. and Herrmann, F. (2015) Affiliative and Aggressive Humour in Leadership and Their Relationship to Leader-Member Exchange. Journal of Occupational and Organizational Psychology, 88, 108-125.

http://dx.doi.org/10.1111/joop.12081 